\title{
A Multilevel Framework and Method for Learning Analytics Integrated Learning Design
}

\author{
Nancy Law ${ }^{1}$, Leming Liang ${ }^{2}$
}

\begin{abstract}
Efforts to realize the potential of learning analytics (LA) to contribute to improving student learning and learning design have brought important advances. A review of successful cases of learning analytics applications reveals that 1) there is a tight coupling between the learning outcome (LO) goals, task sequence design, and the learning analytics and feedback in each case, and 2) the learning analytics to be deployed and the feedback to be provided to learners and/or teachers are integral to the learning design (LD) rather than constructed after the LD is completed. Learning design frameworks in the literature have focused on generic learning task taxonomies and are unable to scaffold LA-integrated LD practice. This paper proposes a multilevel framework for LA-integrated LD, which provides a hierarchically nested multilevel structure for the design of LD and LA elements based on 60 STEM curriculum units collected from authentic classrooms. The framework includes a design process model in the form of a Learning Design Triangle and the concept of Learning Analytics integrated Curriculum Component Design Patterns (LACCDP). Operationalization of the framework is illustrated using one STEM curriculum unit. This framework can be adopted for professional learning and technology development to support LA-integrated LD practices.
\end{abstract}

\section{Notes for Practice}

- For learning analytics (LA) to be effectively deployed to support learning and teaching, it needs to be fully integrated into the learning design (LD) process and not added in as an afterthought. An LA design component should be an integral part of an LD design framework.

- LD is a complex, hierarchically nested, multilevel process from the course level all the way down to the detailed designs within each task, including social organization and individual resources. Coherence and alignment across the different levels and elements of the design are important for the LD to be effective.

- LD decisions for different design elements at different levels should be underpinned by learningsciences-grounded pedagogic principles.

- LD frameworks should provide explicit support to guide teachers and other LD professionals through the multilevel (co-)design process and facilitate the construction of mechanisms to promote pedagogical alignment across the design levels and elements.

- An LA-integrated LD framework should support the documentation of Learning Analytics integrated Curriculum Component Design Patterns (LA-CCDP) to achieve effective learning for specific learning outcomes. These patterns could serve as the "low-hanging fruit" for teachers' adoption of LA in their teaching practice.

\section{Keywords}

Multilevel learning design taxonomy, learning analytics taxonomy, inquiry-oriented learning design, integrated LD-LA framework, Learning Analytics integrated Curriculum Component Design Patterns (LA-CCDP)

Submitted: 14/10/19 - Accepted: 27/04/20 - Published: 17/12/20

Corresponding author ${ }^{1}$ Email: nlaw@hku.hk Address: Center for Information Technology in Education, Faculty of Education, University of Hong Kong, Pokfulam, Hong Kong, ORCID ID: https://orcid.org/0000-0003-3044-0528

2Email:Imliangc@hku.hk Address: Center for Information Technology in Education, Faculty of Education, University of Hong Kong, Pokfulam, Hong Kong, ORCID ID: https://orcid.org/0000-0001-8961-4540

\section{Introduction}

The ultimate goal of learning analytics (LA) is to gain a better understanding of student learning within educational contexts and to provide intelligence to learners, teachers, and administrators to improve learning. Learning design (LD) has been identified as an important conduit to achieve this goal as it provides the necessary context for the sense-making and 
interpretation of the analytics, and for the provision of appropriate feedback to influence learning and teaching. The workshop on connecting learning analytics with learning design in LAK '12 (Lockyer \& Dawson, 2012) is among the earliest documented efforts to call the LA community's attention to this area of research. Since then, there have been increasing interests and interdisciplinary efforts to realize the anticipated potential of learning analytics to provide evidence-based feedback to learners and teachers to enhance learning and learning design. This paper is a response to Mangaroska and Giannakos's (2019) call for the development of a framework to systematically capture learning design data that is grounded in learning analytics and learning theory. Before introducing the framework and demonstrating how it can be operationalized in authentic curriculum contexts, we need to explain our perspective on the purpose and requirements for developing such a framework. We do so by grounding the development of the framework on our interpretation of the key advances and critical gaps in research in this area based on the rich published literature.

\subsection{From Theoretical Exploration to Demonstrated Influence of Learning Design on Learning Behaviour}

Lockyer, Heathcote, and Dawson (2013) rightly point out the need for a formalism to document learning design in order to provide the necessary information about the learning context for the selection, design, and deployment of LA. Our paper identifies three core elements as essential for documenting intentions in learning design: learning resources, tasks, and support mechanisms. It also provides an illustration of how checkpoint and process analytics can be mapped to different points in the designed learning sequence for a case-based learning design represented using the above three design elements, and how the resulting analytics can be used to inform teachers about learner engagement during the learning process and possible ways to improve the design.

In order to seek empirical evidence that learning design influences student learning behaviour, Rienties, Nguyen, Holmes, and Reedy (2017) critically reviewed the data collected from eight large-scale studies conducted at the Open University UK (OUUK) to examine the relationships between the learning design and learning analytics measures captured. OUUK adopts an LD framework (referred to as OULDI) that categorizes learning activities into seven broad categories: 1) assimilative, 2) finding and handling information, 3) communicative, 4) productive, 5) experiential, 6) interactive/adaptive, and 7) assessment. An estimated time needed for students to complete each of the activities per week is also recorded in the LD system. Rienties et al. (2017) report that while learning designs strongly predicted student online learning behaviour and performance, the activity types receiving the highest learner satisfaction ratings were pedagogically very different from those found to correlate highly with learner performance. Based on the findings, the authors further point out the need for refinement in the LD framework so that LA can provide fine-grained pedagogical feedback to teachers and learners.

\subsection{Learning Analytics Implementation as a Co-Design Partnership With Teachers}

The challenge of embedding $\mathrm{AI}$ in authentic learning and teaching contexts is not just a technical one but includes related human challenges that are cognitive, social, organizational, and political in nature (Buckingham Shum, Ferguson, \& MartinezMaldonado, 2019). At the cognitive level, the adoption and interpretation of LA require a range of literacies at some level of sophistication: design literacy, digital literacy, assessment literacy, and data literacy. Thus, there is an emerging recognition that even for well-developed learning analytics tools shown to be capable of providing appropriate feedback to learners, their effective adoption and integration in authentic educational contexts requires a process of pedagogical innovation with teachers participating as partners in the innovation co-design process (Rosé, McLaughlin, Liu, \& Koedinger, 2019). The role of LA as a technology tool is often not simply to improve the efficacy of an established process, but to support new ways of learning and teaching.

For the LA adoption process to be successful, teachers not only need to learn new knowledge and skills, but also need to engage in pedagogical innovation - adopting practices and approaches that may be foreign to their established pedagogical repertoire (e.g., law teachers learning about the pedagogical value of teaching rhetorical moves and using writing analytics to provide feedback to students; Shibani, Knight, Buckingham Shum, \& Ryan, 2017; Shibani, Knight, \& Buckingham Shum, 2019). Engaging teachers and other LD professionals in the co-design of LA tools (Ahn, Campos, Hays, \& DiGiacomo, 2019) as well as in their implementation (Rehrey, Shepard, Hostetter, Reynolds, \& Groth, 2019; Shibani et al., 2017) have been found to be important in ensuring the appropriate design and integration of the LA tools and interpretation of the results and visualizations in authentic contexts in an iterative productive process.

It is noteworthy that all the papers included in the special section on human-centred learning analytics in Vol. 6(2) of the $J L A$ include teachers among the stakeholders involved in the design process, and some also include data scientists, userinterface designers, and LA researchers. In the editorial, Buckingham Shum et al. (2019) conclude that LA should not be something done to teachers or learners, but should be done with the involved stakeholders. Rosé et al. (2019) further advocate that LA research should seek to develop "explanatory learner models" in order to ensure the actionability and interpretability of LA efforts, and identify the establishment of an interdisciplinary "learning engineering team" comprising technologists, education professionals, learning scientists, and design experts as an essential condition. Beyond the anticipated pedagogical 
benefits, the construction of explanatory learner models is also expected to advance theory building and improve pedagogical models in the learning sciences.

\subsection{Robust Technology Pedagogical Content Knowledge Underpinning Successful Cases of Design-Based LA Implementation}

A major challenge to LA is to realize the promise of generating actionable interventions based on LA results to improve student learning outcomes (LOs), which is often referred to as closing the loop (Corrin et al., 2016; Koedinger, Stamper, McLaughlin, \& Nixon, 2013). To gain insight into the features of studies that can successfully close the loop, we need to study cases where LA is embedded into the learning environment for real-time feedback. Mangaroska and Giannakos (2019) conducted a systematic review of analytics-driven learning design to enhance learning published from 2010 to 2017. Of the search results from seven large databases, only 43 papers met their inclusion criteria of being empirical studies involving teachers and/or students as research targets, using data analysis to address issues in educational practice, published in English, and including an abstract. The review found that few analytics designs were explicitly connected to pedagogical models, and that the information generated by LA tools is often misaligned with the needs and concerns of teachers.

Mangaroska and Giannakos's (2019) study finds that among the publications included in their systematic literature review, only a few have LA integrated into the LD to provide real-time feedback to learners and/or teachers. We have identified several cases belonging to this category reported in the recent literature that have successfully led to improved learning outcomes and that provide details about the learning design, the pedagogical implementation, and the specifics of the LA used (e.g., Liu \& Koedinger, 2017; Shibani et al., 2019; Mavrikis, Geraniou, Gutierrez Santos, \& Poulovassilis, 2019; Haya, Daems, Malzahn, Castellanos, \& Hoppe, 2015). Careful analysis of these cases found distinct similarities that could explain their success. Each case is driven by the development of an actionable LA-integrated LD "package," which can be referred to as a curriculum component since each addresses a very specific learning outcome in the curriculum. A careful examination of these curriculum components reveals that each contains a tightly coupled set of learning task sequences, resources, LA tools, and feedback mechanisms to address a specific learning outcome. Further analysis shows that each component comprises technological, pedagogical, and content knowledge artifacts that are coherently connected and underpinned by pedagogical principles grounded in the learning sciences. This has a strong parallel to Koehler and Mishra's (2009) thesis that teachers need to possess the relevant technological pedagogical and content knowledge (TPACK) to be able to make appropriate use of digital technology to support student learning. This TPACK framework has since been widely adopted in teacher education programs as well as empirical studies on teacher learning. Such an exciting parallel shows that LA, as a technology to support learning, also needs to be fully integrated into a curriculum component that comprises a combination of technological-pedagogicalcontent knowledge artifacts (a TPACK composite for short) to achieve the desired pedagogical impact.

This discovery of curriculum components in the form of TPACK composites in successful cases of LA-integrated LD has important implications for the development of an LD framework capable of supporting the integrated design of appropriate actionable LA. In this section, we illustrate what a TPACK composite is (see Table 1) through identifying these in two of the cases reported in the literature: Liu and Koedinger (2017) and Shibani et al. (2019). To do this, we analyze the curriculum component described in each paper according to 1) the learning outcomes targeted by the component, 2) the particular learning challenge to be addressed in order to improve learning, 3) the LA technique deployed for the analysis of learner data and generation of feedback, 4) the task design sequence, and 5) the role of learning sciences in the design and implementation of the LA-integrated curriculum component.

In the case reported by Liu and Koedinger (2017; to be referred to as Case A), the targeted learning outcome was the topic of area calculation of a circle in mathematics. The authors believed that the achievement of this learning outcome depends on student mastery of particular facts, skills, and principles, which the authors referred to as knowledge components (KC). To discover the KCs required for this learning outcome, the authors adopted an educational data mining technique named Learning Factors Analysis (LFA), an automated data-driven method to analyze the data collected from an intelligent tutoring system (ITS) as used by US high school students for geometry learning. The analysis revealed two KCs that differentiate forward and backward calculation of area for circles and squares. Based on these findings, they interpreted the difficulties encountered by high school students to be mainly related to the backward calculation of the radius from the circle area. The online geometry tutor was then redesigned to give more practice time to the backward calculation and improvements were also made to the interface and hints to address this difficulty. Liu and Koedinger (2017) reported significantly higher learning gains for students using the revised system.

In the case reported by Shibani et al. (2017; to be referred to as Case B), the targeted learning outcome was to develop undergraduate law students' genre-specific skills. The ability to recognize rhetorical moves and structures for specific genres is important for particular disciplines or professions and an essential skill for students to learn. The target students needed to learn how to write argumentative law. A writing analytics tool was used to identify the presence and appropriateness of rhetorical structures in text. The writing analytic tool was able to conduct analysis for different genres based on the rubric and 
linguistic information provided. The intervention was designed as a modification of a well-designed four-step task sequence (see Table 1). The writing analytic tool was introduced in Step 4, when students had to revise the low-quality example essay. Students were able to seek feedback on any of their draft revisions at any time. Students found the intervention to be useful in helping them to understand the rubric and in the deliberate practice of their writing skills.

Table 1. Analysis of the Curriculum Components in Two Successful "Completing the Loop" Cases

\begin{tabular}{|c|c|c|c|c|c|}
\hline & $\begin{array}{l}\text { Targeted } \\
\text { Learning } \\
\text { Outcomes } \\
\end{array}$ & $\begin{array}{l}\text { Challenge to } \\
\text { Learners }\end{array}$ & LA Technique & Task Design Sequence & $\begin{array}{c}\text { Role of } \\
\text { Learning } \\
\text { Sciences } \\
\end{array}$ \\
\hline $\begin{array}{l}\text { TPACK }^{1} \\
\text { Focus }\end{array}$ & Content & $\begin{array}{l}\text { Pedagogical }+ \\
\text { Content }\end{array}$ & Technological & Learning design knowledge (TPACK) & $\begin{array}{l}\text { Underpinning } \\
\text { learning theory }\end{array}$ \\
\hline Case $\mathrm{A}^{2}$ & $\begin{array}{l}\text { Calculation } \\
\text { of the area } \\
\text { of a circle }\end{array}$ & $\begin{array}{l}\text { Difficulty in } \\
\text { finding radius } \\
\text { of a given } \\
\text { circle area }\end{array}$ & $\begin{array}{l}\text { Learning } \\
\text { Factors } \\
\text { Analysis (LFA) }\end{array}$ & $\begin{array}{l}\text { In an online geometry Intelligent } \\
\text { Tutoring System (ITS), LFA discovered } \\
\text { two knowledge components that } \\
\text { differentiate forward and backward } \\
\text { calculation of area for circles. } \\
\text { Redesigned ITS to provide more } \\
\text { practice time on backward calculation, } \\
\text { modified interface, and hints to } \\
\text { strengthen backward calculation } \\
\text { support. }\end{array}$ & $\begin{array}{l}\text { Interpretation of } \\
\text { LFA results, } \\
\text { redesign of ITS }\end{array}$ \\
\hline Case $\mathrm{B}^{3}$ & $\begin{array}{l}\text { Genre- } \\
\text { specific } \\
\text { writing skill }\end{array}$ & $\begin{array}{l}\text { Difficulty in } \\
\text { recognizing } \\
\text { and using } \\
\text { rhetorical } \\
\text { structures }\end{array}$ & $\begin{array}{l}\text { Writing } \\
\text { analytics }\end{array}$ & $\begin{array}{l}\text { Task sequence based on related } \\
\text { language learning and pedagogical } \\
\text { design principles: } \\
\text { Matching exercise to promote } \\
\text { understanding of the rubric. } \\
\text { Review of instructor's revisions on a } \\
\text { sample to develop an understanding of } \\
\text { how rhetorical structures can be } \\
\text { improved. } \\
\text { Assess a low-quality example essay to } \\
\text { develop evaluative expertise using the } \\
\text { given rubric. } \\
\text { Revise the scored example essays to } \\
\text { improve areas that students have } \\
\text { identified as inadequate. Students can } \\
\text { seek feedback from the analytics tool } \\
\text { on any draft at any time. }\end{array}$ & $\begin{array}{l}\text { Identify learner } \\
\text { difficulties with } \\
\text { rhetorical } \\
\text { structures, } \\
\text { design of } \\
\text { scoring rubric } \\
\text { for writing, } \\
\text { iterative } \\
\text { redesign of } \\
\text { learning tasks }\end{array}$ \\
\hline
\end{tabular}

${ }^{1}$ TPACK stands for Technological Pedagogical and Content Knowledge

${ }^{2}$ Liu \& Koedinger (2017)

${ }^{3}$ Shibani, Knight, Buckingham Shum, \& Ryan (2017)

We can see that, in both cases, the LA tools were tightly integrated into the design of the learning task sequence to address a specific content goal. Further, the design of the curriculum components in these two cases were informed by technological pedagogical content knowledge derived from robust educational research underpinned by theories of learning in the learning sciences. While each of the LA tools can be used to address a class of analytic questions and can be used for many different learning contexts, the successful loop cannot be repeated if the LA tool is used outside of the tightly coupled component. It is not that the experience and tools generated in these two cases cannot be transferred to other situations. However, any transfer must be bounded by the TPACK context of the original case. For example, in Case A, the LFA can be used to analyze student data to discover students' learning difficulties based on the knowledge components involved. Completing the loop in a new context requires a new round of interpretation of the analytic results and the redesign of the intervention involving learning sciences researchers, teachers, and instructional designers. In Case B, the writing analytics tool and the task sequence could possibly be transferred to another context requiring student ability to recognize and use specific rhetorical structures for a given genre in their disciplinary/professional context. Again, in this case, the writing analytics tool cannot be transferred without appropriate adaptation involving another round of interprofessional collaboration in co-design. 
Due to space limitations, we cannot provide more examples. However, we have conducted similar analyses on two further papers that provide similarly detailed descriptions and we have been able to identify similar TPACK composites in the curriculum components in those cases. The discovery of these LA-integrated curriculum components in the form of TPACK Composites has important implications for the development of a conceptual framework for LD-oriented LA. It calls for the framework to be able to specify an LA-integrated LD pattern at the level of a curriculum component anchoring around a set of coherent TPACK specifications. This will be discussed in a later section as part of the proposed LA integrated LD framework.

\subsection{Emerging Features of a Learning Analytics Taxonomy}

With the rapid expansion of LA as a research field and the ever-increasing analytics techniques available, there is an emerging need for a systematic framework to document and locate different LA tools and initiatives within the broader LA landscape. Several research articles in recent years have proposed taxonomies for classifying and conceptualizing LA (Gibson, Kitto, \& Willis, 2014; Nguyen, Gardner, \& Sheridan, 2017; Mangaroska \& Giannakos, 2019; Peña-Ayala, 2018). While these published LA taxonomies differ in their range of perspectives, at the core they all comprise similar key descriptive dimensions that characterize the purpose of the LA application (e.g., prediction of students at risk, assessment, feedback), what measures are used in the analysis (e.g., learner behaviour, student produced artifacts such as forum posting and reflective writing, and survey data), and the techniques and tools used (e.g., regression analysis, writing analytics).

Peña-Ayala's (2018) proposed taxonomy comprises functionalities, learner analysis, and resources. Functionalities refer to the purposes for deploying LA (e.g., prediction of performance, feedback); learner analysis sheds light on the learners' characteristics, behaviour, and learning support required; and resources refer to interfaces and tools necessary for LA implementation and database used for exploitation by LA tools and methods. Nguyen, Gardner, and Sheridan (2017) proposed a multilayered taxonomy to capture these four different dimensions (or aspects) of an LA application: 1) the objective layer, 2) the data layer, 3) the stakeholder layer, and 4) the instrument layer. The objective layer refers to the purposes of the LA application, which may be learner-centric (data and inference about the learner), event-centric (e.g., understanding the learning interactions), or content-centric (e.g., evaluation of the usefulness of the resources). The data layer refers to the data sources needed/available, such as static data (e.g., learner background) stored in a database, online log data on a learning management system, and dynamic real-time capture of data (e.g., eye tracking). The stakeholder layer focuses on the people informed by and benefitting from LA, such as students, teachers, researchers, administrators, etc. Lastly, the instrument layer refers to the theories and techniques underpinning an LA application. Neither Peña-Ayala's (2018) nor Nguyen et al.'s (2017) taxonomy provides descriptions of the pedagogical or LD context for the LA application(s) concerned, even though an important purpose of the taxonomy was to provide a comprehensive description of what LA techniques can be offered to students, teachers, and instructional designers.

Some LA taxonomies also serve a communicative function to bridge LA and LD through integrating LD-related constructs into the LA taxonomy. Gibson, Kitto, and Wills's (2014) Cognitive Operation framework for Analytics (COPA) is one such example. The COPA framework is underpinned by the revised Bloom's Taxonomy (Krathwohl, 2002), which constitutes the learning objectives categorization in the taxonomy. Seufert, Meier, Soellner, and Rietsche (2019) also argue that the categorization of LA objectives needs to be connected to important pedagogical concerns. There are four categories of analytic objectives in their LA taxonomy arranged in a $2 \times 2$ matrix, reflecting two focal dimensions in trying to understand student learning: the context of learning (individual vs. social) and the analytic purpose (providing prediction vs. supporting reflection). An example of LA that belongs to the social-reflection quadrant of the matrix is the use of social network analysis of discussion forum participation data as a reflection stimulus to encourage more active and balanced contributions from students.

\subsection{Learning Design Taxonomies}

The OULDI developed an LD taxonomy that has been used extensively for documenting a wide variety of courses in authentic contexts (Cross, Galley, Brasher, \& Weller, 2012; Toetenel \& Rienties, 2016). As mentioned in Section 1.1, it comprises seven types of learning activities. This taxonomy was helpful in providing an overall picture of how LD may influence student engagement in different learning activities and how that may affect their measured learning outcomes (Rienties \& Toetenel, 2016). Using K-means cluster analysis of the time distribution across the seven activity types in 87 modules, Rienties, Toetenel, and Bryan (2015) identified four distinct clusters, which were given pedagogical interpretations and labelled respectively as constructivist, assessment-driven, balanced variety, and social constructivist. It was also found that providing teachers with the visualizations of their initial designs using the OULDI taxonomy influenced their final design decisions (Toetenel \& Rienties, 2016).

Task/activity sequence and design are major foci in both LD practice and literature. The positive findings from the OULDI research provide evidence of the pedagogical utility of this type of LD taxonomy. However, its usefulness is limited by the level of detail available about the LD. It can only provide proxies for student engagement in the form of crude aggregates such as total time spent on a task or number of clicks made by the learner. While distribution charts of LD activity types may 
stimulate teacher reflection and design change, this type of representation does not provide information about the design thinking or more nuanced pedagogical considerations made. There is no perfect/magic task distribution profile. What is reasonable or appropriate depends on many factors, including the learning context and the kind of learning outcome goals targeted. Rienties et al. (2017) report that the LD as captured by the OULDI framework differ considerably across disciplines, and present evidence on the risks of applying this framework uniformly across different disciplines. In conclusion, Rienties et al. (2017) point out the need for LD approaches to provide finer-grained representations about the nuanced differences in the design of an activity category (e.g., assessments can involve different activities and can be formative or summative).

Charlton, Magoulas, and Laurillard (2012) took an innovative approach to LD - putting the focus on LD as a digital artifact and providing a software environment to support the design process. The design of the software platform, named Learning Designer, is underpinned by Laurillard's (2013) Conversational Framework. The LDs as designed artifacts can be used to support teacher reflection and design revisions. The Learning Designer, in addition to serving as a design tool, also serves as a repository of LDs as shareable artifacts and supports teacher collaboration in LD as a community of learning design practitioners. The Learning Designer is designed as an intelligent platform that can make pedagogically grounded recommendations to teacher-designers based on semantic technologies, especially an LD ontology. An ontology is a specification of a conceptualization (Gruber, 1995) used in the field of Artificial Intelligence to refer to a formal description of a set of concept definitions. Ontologies are designed to enable knowledge sharing and reuse, as well as for supporting automated reasoning.

The LD ontology underpinning the Learning Designer can be interpreted as a formalized LD conceptual framework or taxonomy (Charlton et al., 2012). At the core of this ontology are the hierarchically nested constructs of Learning Approach, Teaching and Learning Activity (TLA), and Learning Process. Learning Approach is an abstract concept that pertains to the roles of the teacher and learners in relation to how the learning is structured. There are nine Learning Approaches in this ontology: 1) didactic instruction, 2) inquiry-based learning, 3) social constructivism, 4) experiential learning, 5) constructionism, 6) collaborative learning, 7) guided discovery learning, 8) problem-based learning, and 9) cognitive apprenticeship. Each Learning Approach is associated with several learning outcomes (which could be cognitive or affective in nature) and TLAs. TLAs generally comprise a few Learning Processes involving students interacting with tools, resources, and/or among themselves to achieve a set learning outcome in a session. There are five types of learning processes in this framework: 1) acquisition, 2) discussion, 3) inquiry, 4) production, and 5) practice. An example of a social constructivist TLA is a "tutor-supported group discussion" comprising three Learning Processes: a tutor presentation (acquisition), student production online (posting to a forum), and tutor guided class discussion on VLE communication tools (discussion). The ontology also comprises many contextual details such as class size, total course hours, etc.

The two LD frameworks reviewed in this section are very different in terms of their complexity. The OULDI taxonomy essentially focuses on capturing design at the Learning Processes level in the Learning Designer ontology. Law et al. (2017) put forward a pattern language-based learning design tool — named the Learning Design Studio — to provide pedagogically grounded support to the LD process. The proposed pattern language was inspired by Alexander's (1977) pattern language conceptualization around architectural design, which has a hierarchically nested structure for the design patterns. Law et al.'s (2017) LD pattern language can be interpreted as an LD taxonomy, which comprises several levels - course, units, and tasks - and decisions at each level should be guided by appropriate pedagogical underpinnings. They also put forward the idea that learning design tools should provide an interface to LA systems such that LA can be "design-aware."

The literature on LD frameworks shows a general recognition of the importance of having an appropriate taxonomy to guide the LD process. Published taxonomies aim to provide pedagogical support to teachers and learning designers, but differ in their complexity and structure. Law et al. (2017) put forward the idea that an LD taxonomy can serve to provide an interface with LA systems, but they have not provided details on how that could be achieved.

\section{Multilevel Framework for LA Integrated LD: Purpose and Requirements}

The LA-integrated LD framework we propose in this paper aims to serve four purposes: 1) as a taxonomy that can capture the key pedagogical intentions in the design, operational details in the implementation, as well as the specifications of the LA that can be used to address questions compatible with the design and design intentions; 2) as a conceptual basis for the design of a technology platform and tools that can be used by teachers and other learning designers to design better courses, curriculum units and LA to enhance student learning efficacy; 3 ) as a metacognitive scaffold to guide teachers and other LD professionals in their design practice, and 4) be capable of representing the LA-integrated LDs at the curriculum component level as described in section 1.3.

Based on the above purposes, the corresponding requirements on the conceptual framework are as follows:

1. It must capture the multiple layers (or grain sizes) in the pedagogical reasoning and design decisions encapsulated in an LD (Goodyear, 2005). The layers of pedagogical decision-making here are different from the levels of granularity 
in the learning design/instructional design literature that focuses on delineating the different grain sizes in learning designs as artifacts (e.g., Dalziel, 2013; Hernández-Leo, Harrer, Dodero, Asensio-Pérez, \& Burgos, 2007; Boyle, 2010) to highlight their structural relationship. Goodyear (2005) distinguishes four layers of pedagogical design focus: 1) pedagogical philosophy, 2) high-level pedagogy, 3) pedagogical strategy, and 4) pedagogical tactics. Pedagogical philosophy comprises sets of beliefs, such as instructivism or constructivism, related to the nature of knowledge and how people learn, and influences the learning outcome goal valued. A high-level pedagogy (which we will refer to as pedagogical approach) provides some possible forms of action compatible with the pedagogical philosophy that are appropriate for achieving the intended learning outcome, but does not prescribe action. Problem-based learning and cognitive apprenticeship are examples of pedagogical approaches. A pedagogical strategy provides a broad sketch of what needs to be done to achieve specific outcome objectives. The description of intentions and actions at this level is similar to the TLAs in the Learning Designer ontology described earlier. Pedagogical tactics are also descriptions of action but are at lower levels of granularity compared to pedagogical strategies. It often pertains to particular task settings or designs to achieve the desired effects or outcomes during the implementation phase. This may include the use of motivators such as badges and leader boards, or organizational techniques such as ways of grouping students for different activities. These four levels of pedagogical considerations are loosely coupled since decisions made at one level do not prescribe action at another level. However, decisions made at one level do constrain the range of possibilities at other levels so as to ensure alignment across the decisions made at different levels.

2. If the LA component of the framework is to support and guide the design of analytical questions pertaining to the different levels of LD decisions, it must also have a multilevel structure compatible with that of the LD framework.

3. Within educational settings, teachers often have a relatively clear grasp of the learning outcomes they wish/need to achieve through the implementation of the LD they are developing. They often also hold some established pedagogical philosophy but may or may not have an idea of what pedagogical approach might be appropriate. The biggest challenge in developing an LD is in knowing what pedagogical strategy to adopt and which pedagogical tactics could be used. The framework thus needs to provide a procedural description/guide on how to construct a pedagogically sound LD given a set of learning outcome objectives and a preferred pedagogical approach.

4. In addition to providing a framework that describes the pertinent constructs at different levels of design granularity, the framework should also support the documentation and archiving of LA-integrated curriculum component learning designs, which should comprise descriptions at both the pedagogical strategy and tactics levels.

\section{The Proposed Multilevel Framework for LA-integrated LD Patterns}

In our work, we focus on providing LD decision-making support to teachers to promote their adoption of technology-enhanced social constructivist pedagogies at the philosophical level. In this section, we describe the conceptual framework that we have constructed for this work based on the requirements presented above.

\subsection{Multilevel Design Hierarchy}

From a structural perspective, our framework supports three levels of LD decisions: course/curriculum unit, curriculum component, and learning tasks, which, as we will explain, matches the pedagogical decision hierarchy, defined as approach, strategy, and tactics. We adopt an outcome-based approach to curriculum design (Spady, 1993) in which course planning starts with the specification of learning outcomes, followed by a backward design of learning tasks and assessments to achieve and assess the intended learning outcomes. Learning outcomes are closely related to the subject discipline involved but should not be limited to disciplinary knowledge and skills. Generic outcomes such as 21 st-century skills of communication and collaboration should also be considered. Learning design generally starts at the course/curriculum unit level, with the goal of helping students to achieve a specific set of coherent learning outcomes. The design of a course or curriculum unit also needs to set out the total learner study time (including a specification of the time allocated to structured learning time, either face-toface or online, and the expected self-directed learning time), organizational arrangements such as the number of sessions (or lessons), the time allocated to each session, and any general learning environment support needed for the course or unit.

As mentioned in the previous section, the next level of design is to determine the pedagogical approach that would be compatible for achieving the learning outcome goals of the course or unit. Different approaches generally prioritize a different set of generic learning outcomes, in addition to disciplinary knowledge and skills targeted. A pedagogical approach is often characterized by a design assumption that students would best learn through a sequence of learning foci and experiences, each building up the necessary knowledge, skills, and/or setting for the next experience. For example, a common depiction of selfdirected learning (SDL) comprises the following sequence of curriculum components in the LD: goal setting, self-planning, self-monitoring, self-evaluation, and revision (Pilling-Cormick \& Garrison, 2007; Hew, Law, Wan, Lee, \& Kwok, 2016). Another well-known approach is problem-based learning (PBL), which is often adopted in professional education, such as in 
medical schools. While PBL does not specify exact learning activities or resources to be adopted, it does provide a framework that specifies a sequence of "curriculum components" that should be included. For example, Barrows (1986) provides a fivecomponent model in medical education, comprising 1) observe the patient, 2) generate diagnostic hypothesis, 3) refine diagnostic hypothesis and generate treatment plan, 4) collect observations and data during the "treatment," and 5) final evaluation of the diagnosis and treatment. There are other descriptions of PBL for medical or other disciplines, such as HmeloSilver (2004) and Shuler (2012), which provide largely similar sequences of curriculum components. Each component serves to achieve specific learning outcomes, which may be disciplinary knowledge, disciplinary skills, and/or generic skills.

Pedagogical strategy is a design decision to achieve a specific set of learning objectives by providing a set of learning experiences for the student. For example, "predict-observe-explain" and brainstorming can both be pedagogical strategies for the goal-setting curriculum component in SDL. We refer to the instantiation of a pedagogical strategy as a curriculum component, such as adopting the predict-observe-explain strategy for goal setting in an SDL course/unit.

A pedagogical strategy comprises several learning tasks. For example, the predict-observe-explain strategy usually comprises a sequence of four learning tasks: 1) predict what would happen when an action is taken, 2) conduct experiment and observe, 3) explain whether the observation aligns with the prediction and why, and 4) reflect. For the implementation of a pedagogical strategy to be successful, the task settings — such as the social organization, the use of motivators, etc. — are important. The same learning task can be organized very differently depending on the task settings. A pedagogical strategy will contain guidance in the form of appropriate pedagogical tactics for task setting within the strategy.

In summary, LD is a complex, multilevel activity that requires a multilevel framework. We have provided the description of an LD conceptual framework comprising four levels of granularity in design - from the course or unit level to curriculum components to learning tasks and task settings - with the design decisions at each level guided by pedagogical philosophy, approach, strategy, and tactics respectively. While the description appears to be linear, the actual design process is much less rigid, and iterations/digressions are expected. However, the framework (and preferably a technology platform underpinned by the framework) will help teachers and LD professionals to keep track of their design at these different levels to maintain coherence and alignment across and within the different levels.

\subsection{Task Taxonomy}

In nearly all the LD frameworks reviewed (e.g., Cross et al., 2012; Charlton et al., 2012), the categorization of learning tasks is a core component in the framework. Task taxonomies are important in providing information about the nature of the learning experiences students will have, such as receiving instruction, engaging in inquiry, or exploration. As such, the task taxonomy also provides important LD information for analytic operations as our review in section 1 reveals. There are different ways of categorizing tasks. We have adopted the task taxonomy from Law et al. (2017) as it foregrounds pedagogies advocated for the development of 21 st-century skills. In addition, the taxonomy identifies social organization of learning as a task setting rather than a task type, in recognition of the increasing integration of collaboration and social interaction designs into different task types in LDs. The taxonomy proposed by Law et al. (2017) comprises 12 task types (as shown in Figure 1), which are further grouped into four categories, each comprising three task types.

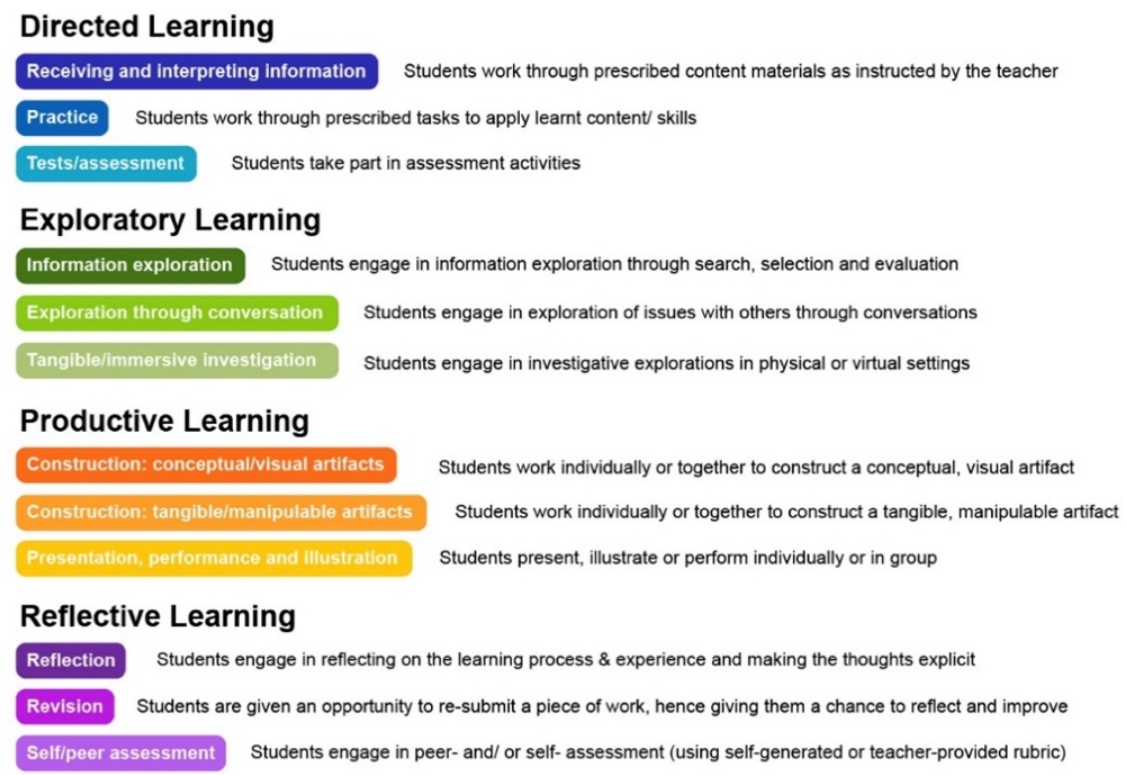

Figure 1. Taxonomy of learning tasks (Law et al., 2017)

ISSN 1929-7750 (online). The Journal of Learning Analytics works under a Creative Commons License, Attribution - NonCommercial-NoDerivs 3.0 Unported (CC BY-NC-ND 3.0) 
The directed learning category includes receiving and interpreting information, practice, and tests/examinations. The exploratory learning category comprises information exploration (e.g., information search and evaluation), exploration through conversations (e.g., face-to-face and forum discussions), and explorations through tangible/immersive investigations (e.g., experiments, simulations, role-plays). The productive learning tasks include three types of creative constructions: conceptual/visual artifacts (e.g., essays, concept maps, artwork), tangible/manipulable artifacts (e.g., models, programs, robotic systems), or performative productions such as oral presentations, dance, drama, etc. The fourth category is reflective learning, which includes three task types: creating a reflection artifact (e.g., a reflection journal, an e-portfolio), revisions of earlier work, or doing peer- or self-assessment.

\subsection{Task Level Design}

A set of vocabularies specifies the settings of each learning task, including social organization, group size, feedback, motivator, duration of the task, activity setting, resources, and tools used. For instance, there are four types of social organization of learning: whole class, individual, peer (e.g., peer assessment, peer teaching), and group work. If group work is adopted, teachers may also specify the group size, and the method for grouping students (e.g., random assignment, student selection, criteria-based assignment) if deemed appropriate for the context of the LD. The format of feedback provided to students is another important design issue at the task level. It can be automated feedback generated by a learning management system (LMS), or peer feedback from a peer assessment activity. The setting of a motivator is a tactic to increase students' learning interests and engagement, such as by providing a badge to reward good performance, or by invoking social recognition by setting up a leader board. The task setting also specifies that mode of learning interaction: face-to-face in a classroom, synchronous or asynchronous online. It also provides descriptions of technologies, tools, and resources needed to support the learning task, such as assessment rubrics, worksheets, concept mapping tools, and LMS functionalities.

\subsection{LA Component of the LD Taxonomy}

As LA should be an integral part of the LD decision-making process, LD design frameworks should include a conceptualization of LA design. For LA to inform and support learning and LD at these different levels, the LA component of the taxonomy should also have a multilevel structure. We propose a conceptual framework for the LA component of an LA-integrated LD framework. It comprises five dimensions: 1) LA functionality, 2) LA measure, 3) data type, 4) LA technique, and 5) stakeholders targeted. The LA specifications for each of these five dimensions need to be stated at the specific LD level when implemented. Figure 2 provides example categories for the five dimensions at three levels: course/unit, curriculum component, and task. However, analytics can also be specified at the task setting level, such as student patterns of engagement with a specific resource or the patterns of social interaction in a discussion forum.

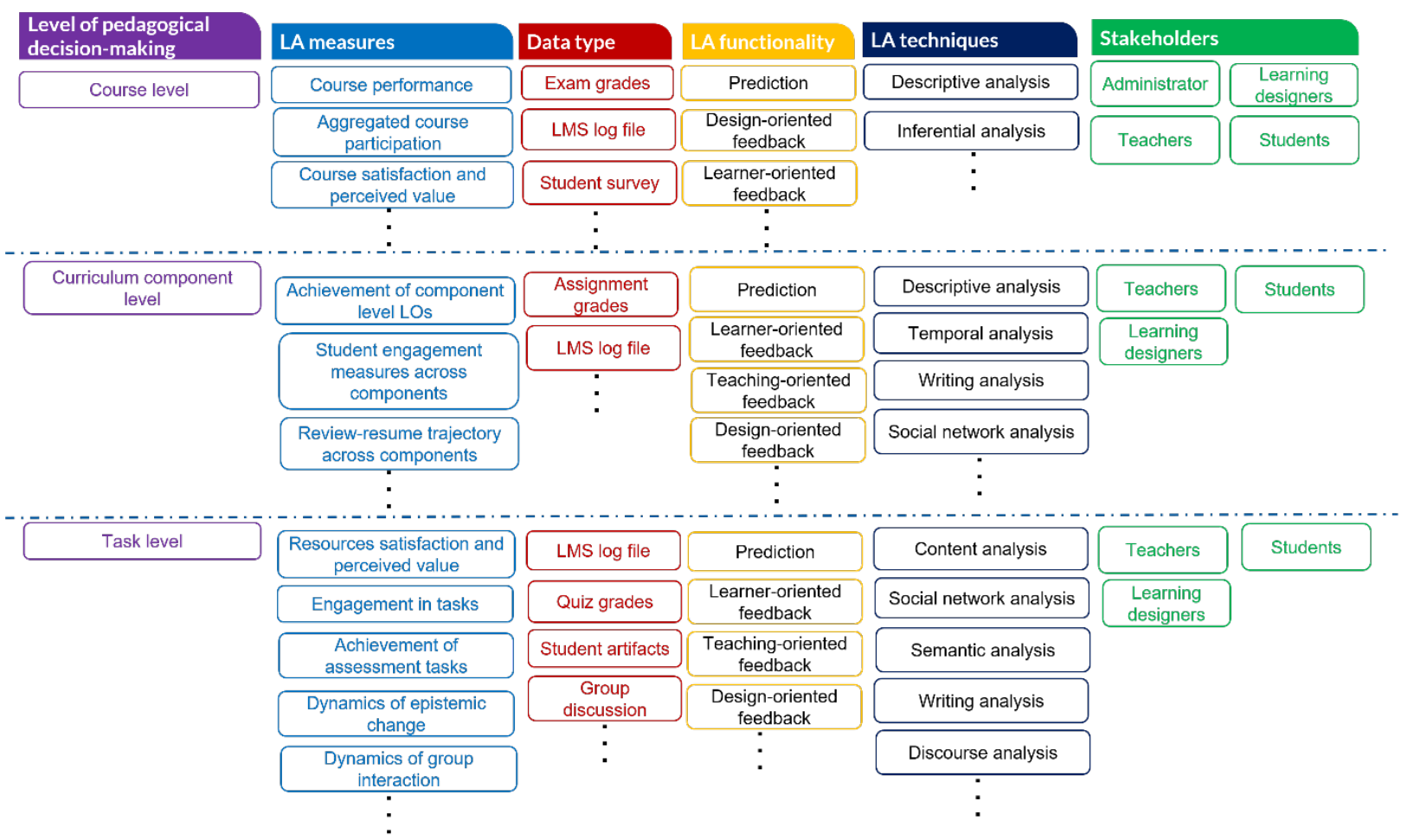

Figure 2. Our LA taxonomy

ISSN 1929-7750 (online). The Journal of Learning Analytics works under a Creative Commons License, Attribution - NonCommercial-NoDerivs 3.0 Unported (CC BY-NC-ND 3.0) 
A guiding principle in our design of this conceptual framework is to recognize the fact that LD-oriented LA questions often pertain to a particular LD level, even though the LA functionality is the same. For example, in predicting performance at the course level, course-level measures - such as students' aggregated participation, satisfaction and perceived value, login and participation statistics - would have to be included. Descriptive analysis and inferential analysis may be used to analyze these data to predict student performance and their risk of drop-out. The results will also provide feedback to students at risk, administrators, and teachers concerned with the overall effectiveness of the course design. LA questions at the curriculum component level will have a more fine-grained focus. Some of the LA techniques will measure student achievement of specific learning outcomes in each curriculum component by examining student performance of an assignment at the end of learning sessions or weeks. In MOOC settings, it may be meaningful to investigate the stop-review-resume trajectory of students' resource access behaviour since they have the autonomy to decide their own learning pathways from one session to another, as well as within a session, thus their access behaviour may differ from the teacher's intentionally designed learning sequence. As the pedagogical underpinnings at each level are already captured in the LD, it is possible to provide LA to inform LD and to support the design and implementation of pedagogically grounded, LA-integrated interventions.

LA questions may also make use of multiple analytic techniques involving data and measures from more than one level. It is important to emphasize that this LA conceptual framework is only illustrative and not exhaustive. It can be enriched as application cases and techniques emerge. An important feature of this conceptual framework is that it can support the construction of LA-integrated LD patterns, as discussed in the next section.

\subsection{LD-LA Connected Design Patterns}

In section 1.3, we report on our identification of LA-integrated curriculum components as productive units for connecting LA to LD with demonstrable success in "completing the loop"; the LA-integrated LD framework should support the specification of LA-integrated LD patterns at the level of a curriculum component anchoring around a set of coherent TPACK specifications. In this section, we elaborate on the concept of LD patterns and how the proposed framework can be used to construct LAintegrated LD patterns. The concept of a design pattern as proposed here was first put forward by Alexander (1977) in the context of architectural design:

[a design pattern] describes a problem which occurs over and over again in our environment, and then describes the core of the solution to that problem, in such a way that you can use this solution a million times over, without ever doing it the same way twice (p. $x$ ).

According to Alexander (1977), a design pattern provides a semi-structured description of the "solution" for a given problem within a particular context. Based on this conceptualization, it is possible to formulate a design pattern for both Cases A and B to support its transfer to situations with similar problems and contexts. This concept has inspired many LD researchers since the early 2000s as the field gained momentum (Goodyear \& Retalis, 2010; Laurillard, 2013; Mor, Mellar, Warburton, \& Winters, 2014). There have been many efforts to use the problem-context-solution format to capture and document learning designs, some of which also incorporate the use of learner data to modify the patterns to suit the specific contexts (e.g., Inventado \& Scupelli, 2015). Technology platforms such as the Learning Designer (Bower, Craft, Laurillard, \& Masterman, 2011) and Learning Design Studio (Law et al., 2017) have also been developed based on Alexander's (1977) design pattern framework to support teacher learning and collaboration in learning design. It should be noted that the granularity of the patterns in the published literature varies greatly from that of a topic to a task or a task setting. There are several important differences between the Learning Analytics integrated Curriculum Component Design Patterns (LA-CCDP) proposed here and the design patterns in the published literature. First, CCDPs are designs at a specific granularity: an LA-CCDP comprises a set of interconnected learning tasks that together address a specific learning outcome. Second, while all learning design patterns following the Alexandrian conceptualization contain information about the learning problem (targeted learning outcome), the context (course and student context), and the solution (task sequence of each LA-CCDP with its underpinning TPACK foci). Third, the LA and associated feedback interventions are fully integrated into the design pattern. Fourth, the conditions for applicability and the elements to be modified for different contexts should be made explicit in the LA-CCDP solution description. In the following section, we will elaborate on the following elements: 1) how the TPACK foci guide the development of Learning Analytics integrated Curriculum Components (LA-CCs); 2) how an LA-CC is a learning design at a specific granularity (within the hierarchy of the course, curriculum component, and task levels); and 3) what kinds of LA can be adopted for each level of granularity. At the end of section 4, we will discuss the relationship between LA-CC and LACCDP.

\section{Illustration of How the Framework Can Be Implemented}

The LD portion of the integrated framework has been developed based on 60 LDs of STEM curriculum units created by

ISSN 1929-7750 (online). The Journal of Learning Analytics works under a Creative Commons License, Attribution - NonCommercial-NoDerivs 3.0 Unported (CC BY-NC-ND 3.0) 
teachers involved in a university-school partnership project from 2017 to 2019. These were collated and archived in a database. This government-funded project aimed to provide support to teachers for developing their capacity to adopt SDL as a pedagogy of choice to promote inquiry-based learning in STEM subjects, and to strengthen students' STEM knowledge, skills, and 21stcentury competencies. Based on our analysis of the 60 LDs and our inferences on how LA can be integrated into the LD process, we have developed inductively an operationalizable 7-step approach to guide teachers' LD practice, and formalized it as a learning design triangle (LDT) framework. It is intended to guide teachers from a starting point when they have broadly identified the learning outcomes for a course/unit to completing the entire LA-integrated LD. In the context of this partnership, the pedagogical approach was already determined to be SDL. We also encourage teachers to structure their LDs as authentic practices in the STEM professions. We thus find that most of the LDs are designed as scientific investigations or engineering designs, which we refer to as disciplinary practices. The LDT then starts with teachers having made decisions about the learning outcomes to be achieved, and the disciplinary practice they wish to model in the inquiry process. Figure 3 provides a visual representation of the 7-step LDT framework for guiding the LD decision-making process. In the remainder of this section, we use one of the 60 archived LDs from the STEM partnership project to illustrate how the 7-step LDT framework can be operationalized in an authentic context. The selected LD was designed as an 11-session curriculum unit for grade 8 students. The title of the unit was "The Science of Cooking."

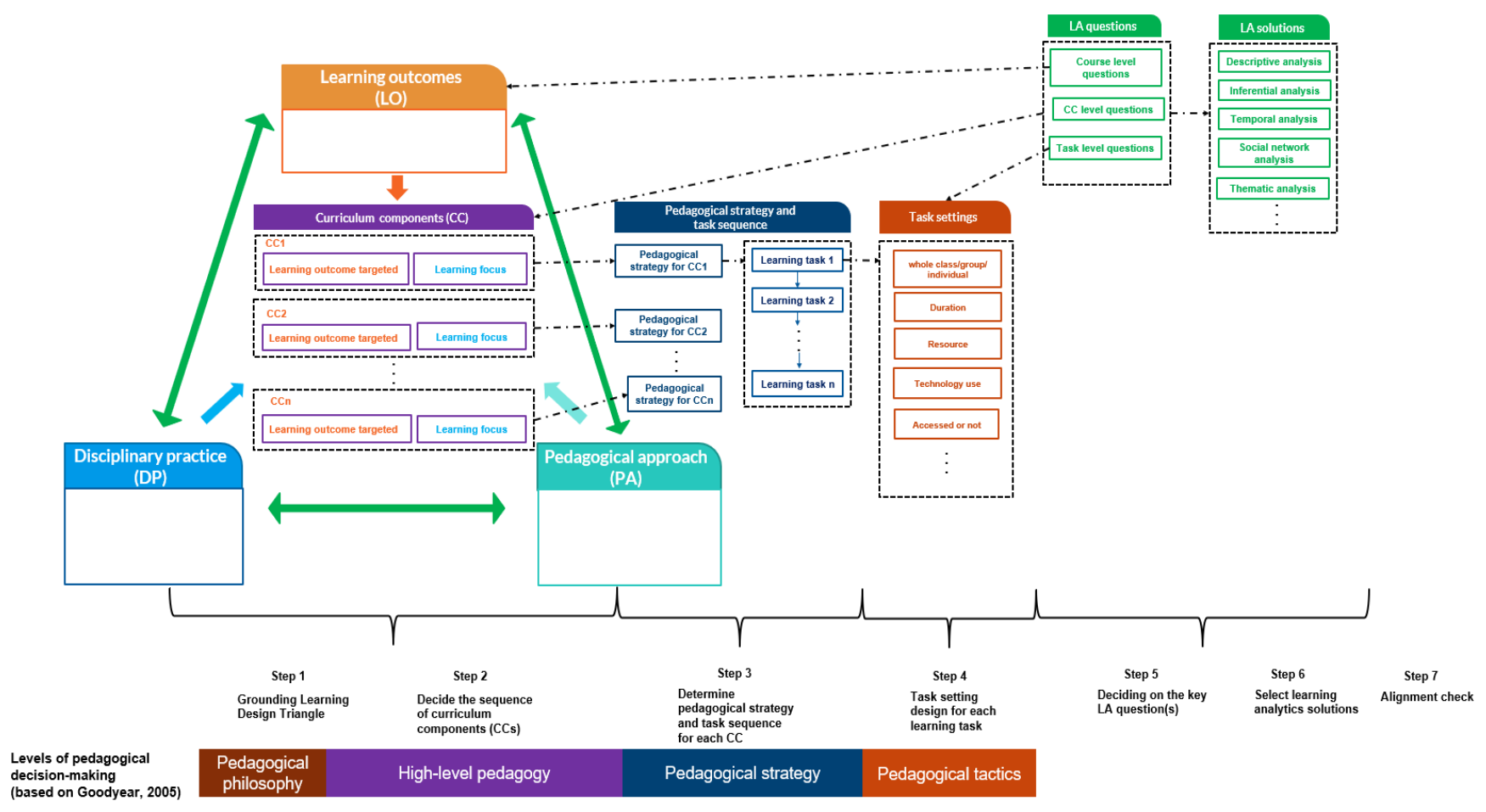

Figure 3. A visual representation of the 7-step LDT framework for guiding the LD decision-making process

\subsection{Step 1: Grounding the Learning Design Triangle}

The LDT serves as a cognitive tool to scaffold design decisions based on a general pedagogical approach (e.g., SDL) and a selected authentic practice format in a disciplinary area to generate curriculum components and further detailed designs to achieve the intended learning outcome goals for the unit. Learning outcomes, disciplinary practice, and pedagogical approach are three key elements to be defined at the start of the design process. Figure 4 illustrates how these three elements are mapped in the LDT framework. For the LD, the teacher selected scientific investigation (SI) as the disciplinary practice for structuring the flow of the SDL inquiry process. In STEM, SI practices generally consist of five main steps: 1) formulate inquiry questions; 2) research and propose hypothesis; 3 ) design and conduct experiments; 4) collect and analyze data, interpret results, and draw conclusions; and 5) communicate findings and formulate further action, such as improving the investigation. The SDL approach adopted in the school partnership STEM project comprises five stages: 1) goal setting, 2) self-planning, 3) selfmonitoring, 4) self-evaluation, and 5) revision (see Figure 5). The intended learning outcomes were scientific knowledge about the five essential nutrients and ways to test for their presence, scientific inquiry skills, and SDL skills. 


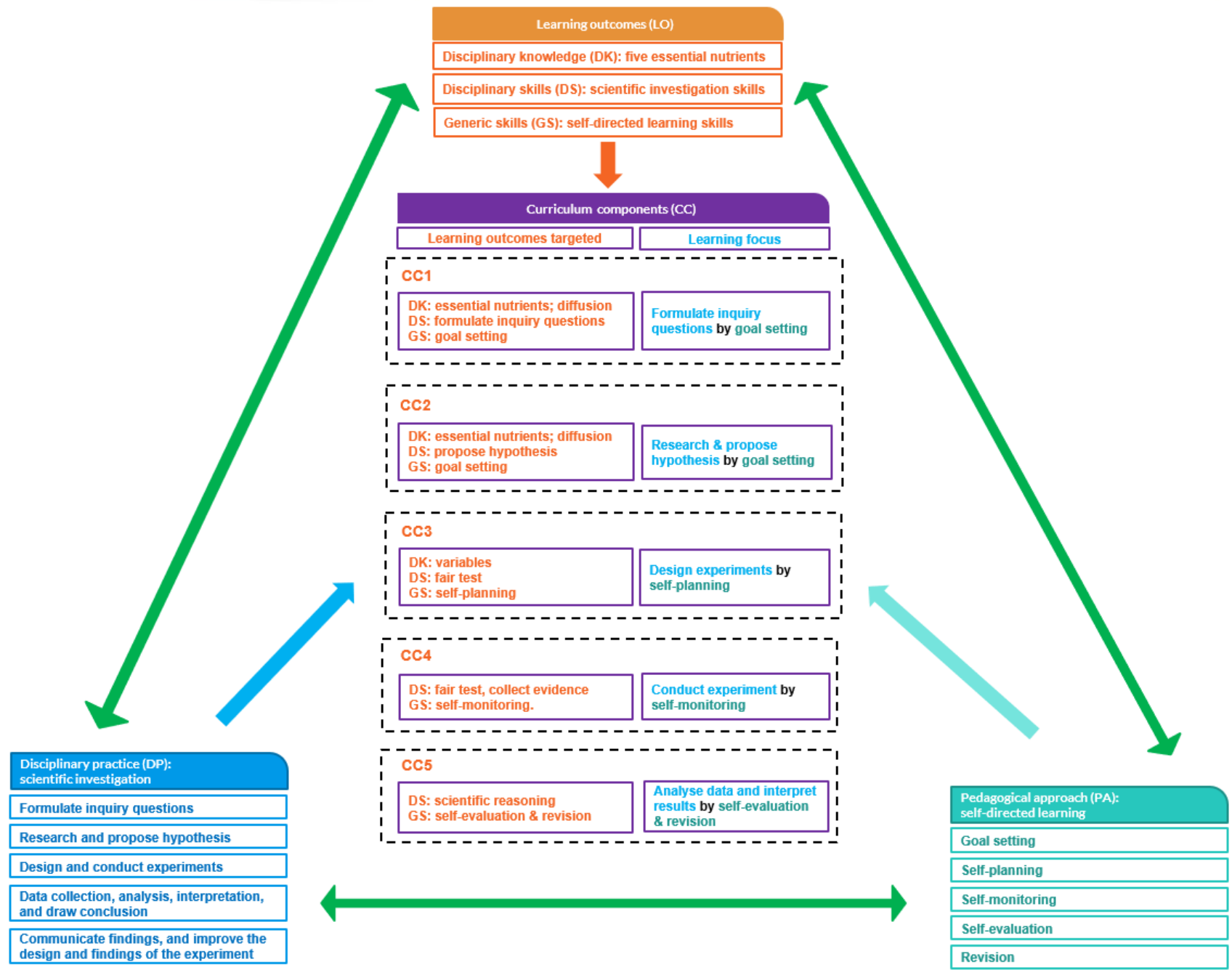

Figure 4. Design triangle for "The Science of Cooking"
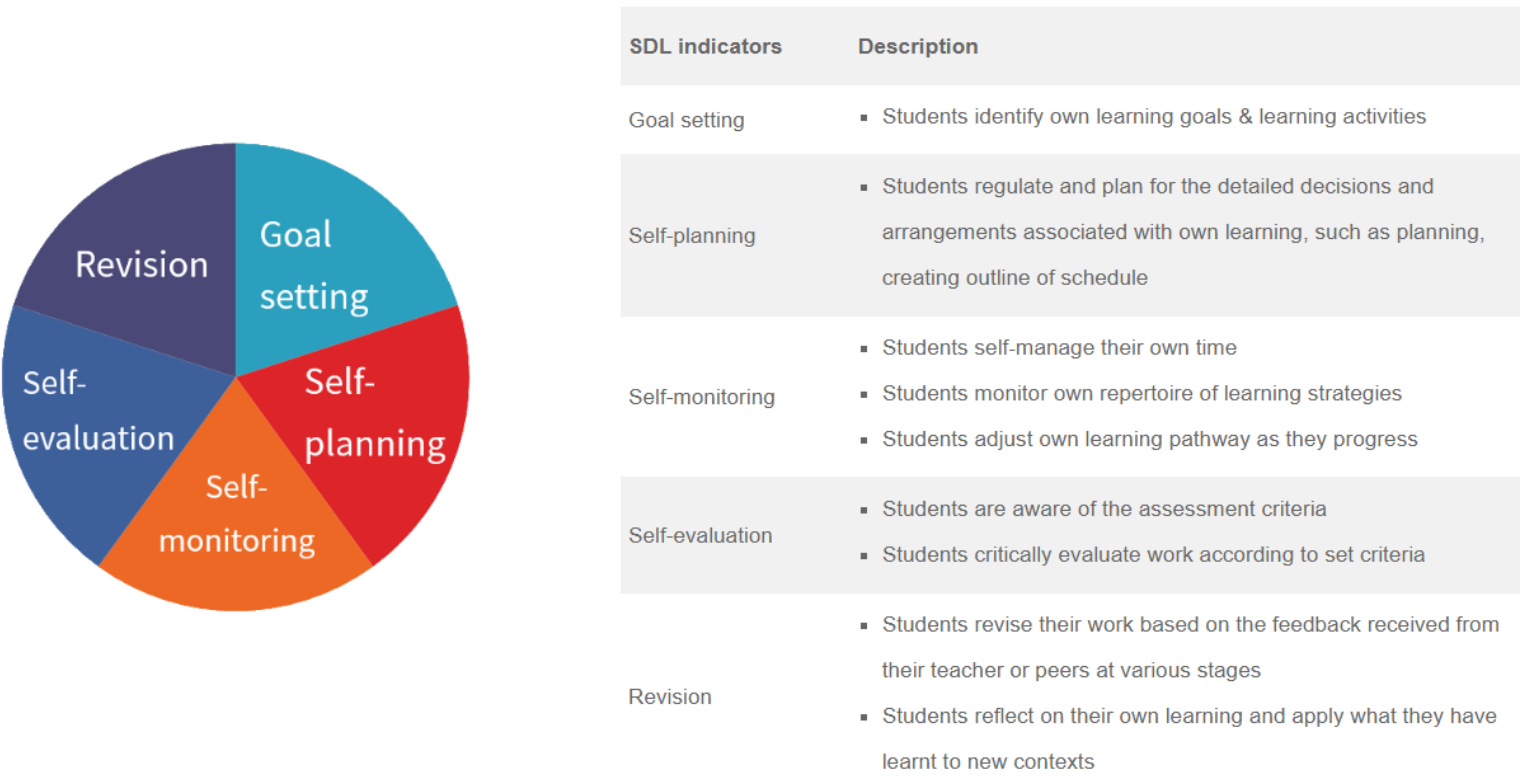

Figure 5. Five key stages in self-directed learning 


\subsection{Step 2: Decide the Sequence of Curriculum Components}

Figure 4 also illustrates how, given the decision to adopt SI as the disciplinary practice and SDL as the pedagogical approach, the curriculum components can be identified and matched with the intended learning outcomes. First, the five steps in SI can be conveniently mapped to the corresponding stages in the SDL approach. In the first curriculum component, students should learn how to formulate a scientific inquiry question by themselves, and propose a hypothesis for the inquiry in the second component. This maps well with the goal-setting step in SDL, and in terms of learning outcomes, students are expected to gain a basic understanding about the five nutrients as well as skills in goal setting through this component. The other four curriculum components are as follows: 1) research and propose a hypothesis as a deepening stage of goal setting; 2) design experiments through self-planning and conduct the experiment through self-monitoring; 3) conduct experiments while exercising selfmonitoring; and 4) analyze data and interpret results through self-evaluation and revision.

\subsection{Step 3: Determine the Pedagogical Strategy and Task Sequence for Each Curriculum Component}

In the ideal situation, there should be a variety of LA-CCDPs available for teachers to consider for adoption and customization for each curriculum component. Step 3 focuses on planning a pedagogical strategy that provides a recommended task sequence encapsulating various learning experiences that teachers can create for students to achieve the learning objectives. Figure 6 shows the pedagogical strategy adopted for each curriculum component. Each task in the sequence belongs to one of the twelve task taxonomies (see Figure 1). Further, the project encourages teachers to adopt assessment as learning (Earl, 2012) in their assessment design. Thus, assessment is not considered to be one of the task types in task taxonomy; rather, teachers may select tasks in their LD to incorporate assessment functions into the design. Technically, teachers can tag any task to an assessment function in the task setting. Within a pedagogical component, the task settings may offer recommendations for assessmentrelated resources, such as rubrics or examples of work. In designing task settings, the teacher can also add or customize such resources.

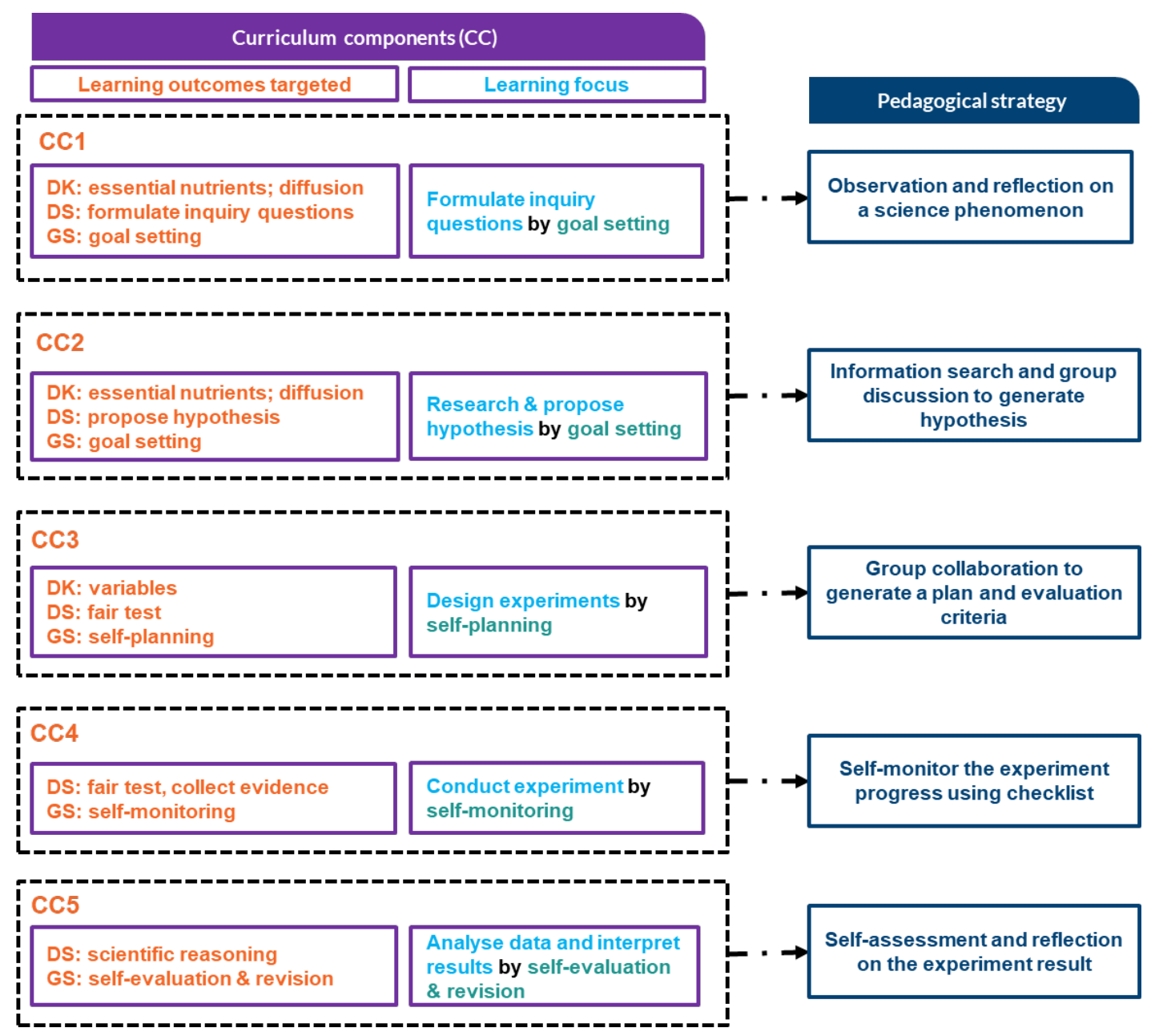

Figure 6. Pedagogical strategy adopted for each curriculum component 
To conserve space, we provide an illustration for the process of designing the pedagogical strategy for the first curriculum component. The pedagogical strategy selected for goal setting is "observation and reflection on a science phenomenon." The strategy comprises a sequence of four tasks (see Figure 7). To begin, the teacher use stimulus materials (possibly multimedia resources such as videos) to raise student interest and engagement in the topic, and the corresponding task type for "students observe the scenarios in the presented stimulus" is "receiving and interpreting information." Students are then asked to work in groups to generate appropriate inquiry questions they consider worth exploring for the topic. The task type for this second task is "exploration through conversation." The final task in the sequence is to formulate inquiry questions and post them to the online discussion forum. As the students must construct inquiry questions, which are conceptual artifacts, the task type is "construction of conceptual artifacts" and belongs to the productive learning category.

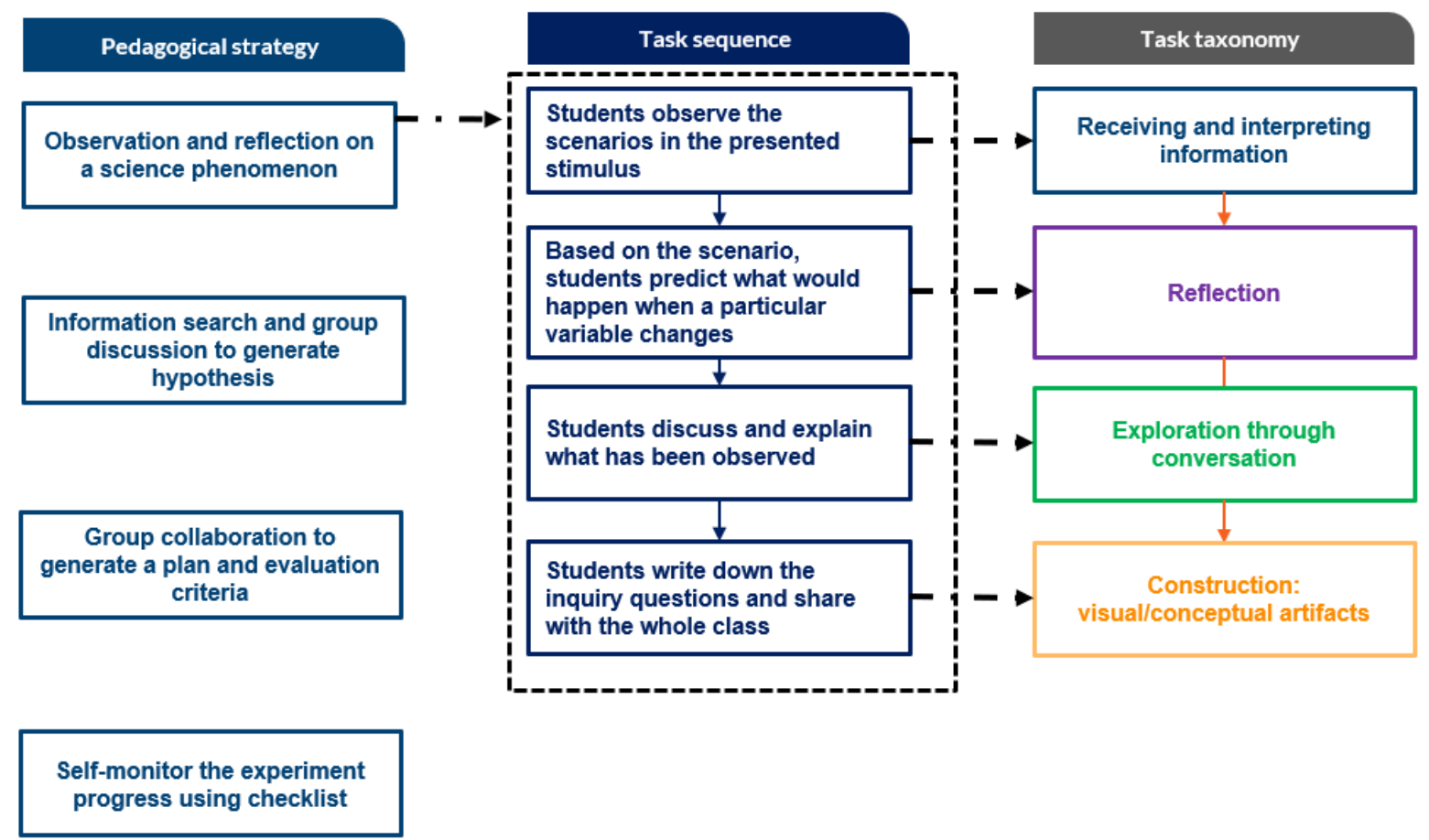

Self-assessment and reflection on the experiment result

Figure 7. The sequence of four learning tasks and their corresponding task types for the pedagogical strategy "observation and reflection on a science phenomenon"

\subsection{Step 4: Task Setting Design for Each Learning Task}

The fourth step is to craft the setting for each learning task for effective implementation. Teachers need to specify the context and detailed arrangements such as the tool(s), resource(s), social organization, physical setting, motivator, time duration, etc. for implementing the task. Taking the "students observe the scenarios in the presented stimulus" task as an example, several pedagogical tactics are suggested, as shown in Table 2. The stimulus resource can be a video, a website, or a news report as long as it is authentic, relevant, and meaningful to learners. Students can use a well-designed worksheet to guide observations and reflections while interacting with the stimulus. The LMS can also be set to generate automated feedback based on the students' video-watching behaviour, and to provide hints about the focal issues to watch for. 
Table 2. Task Setting for "Students Observe the Scenarios in the Presented Stimulus"

\begin{tabular}{ll}
\hline Type of the task & Receiving and interpreting information \\
\hline Title of the task & Students observe the scenarios in the presented stimulus \\
\hline Description of the task & $\begin{array}{l}\text { This task is used to raise student motivation and help } \\
\text { them understand the context of the problem }\end{array}$ \\
\hline Is this an assessment task? & No \\
\hline Social organization & Individual \\
\hline Feedback & Automated feedback \\
\hline Motivators & Individual agency \\
\hline Duration (min) & 5 \\
\hline Setting & Face-to-face (classroom) \\
\hline Resources & Video, website, news, worksheet \\
\hline Tools & Learning management system \\
\hline Notes and observations & $\begin{array}{l}\text { Scenario and learning resources should be authentic, } \\
\text { relevant, and meaningful to learners } \\
\text { Resource example: hyperlinked video }\end{array}$ \\
\hline
\end{tabular}

Table 3. LA Questions for Different Levels of LD Granularity in "The Science of Cooking" Unit

\begin{tabular}{|c|c|c|}
\hline $\begin{array}{l}\text { Levels of } \\
\text { Granularity }\end{array}$ & LA Measures & Example LA Questions \\
\hline \multirow{3}{*}{ Course Level } & $\begin{array}{l}\text { Course performance } \\
\text { (assessment required) }\end{array}$ & $\begin{array}{l}\text { - Do students master the knowledge about specific nutrients? } \\
\text { - Do students master the skills of conducting a scientific investigation? } \\
\text { - How do students perform in the five components of SDL? }\end{array}$ \\
\hline & $\begin{array}{l}\text { Aggregated course } \\
\text { participation }\end{array}$ & $\begin{array}{l}\text { - How many times do students access each online activity and learning } \\
\text { resource? }\end{array}$ \\
\hline & $\begin{array}{l}\text { Course satisfaction and } \\
\text { perceived value }\end{array}$ & $\begin{array}{l}\text { - Are students satisfied with the course design? } \\
\text { - Which part of the design can be improved based on student } \\
\text { feedback? }\end{array}$ \\
\hline \multirow{3}{*}{$\begin{array}{l}\text { Curriculum } \\
\text { Component } \\
\text { Level } \\
\text { (Taking } \\
\text { "Formulate } \\
\text { inquiry } \\
\text { questions by } \\
\text { goal setting" } \\
\text { as an example) }\end{array}$} & $\begin{array}{l}\text { Achievement of component } \\
\text { level LOs (assessment } \\
\text { required) }\end{array}$ & $\begin{array}{l}\text { - Do students master the knowledge about specific nutrients? } \\
\text { - Do students master the skills of formulating inquiry questions? } \\
\text { - Can students set their own learning goals? }\end{array}$ \\
\hline & $\begin{array}{l}\text { Student engagement } \\
\text { measures across components }\end{array}$ & $\begin{array}{l}\text { - Do students access and engage in the components using the intended } \\
\text { sequence? }\end{array}$ \\
\hline & $\begin{array}{l}\text { Stop-review-resume } \\
\text { trajectory across components }\end{array}$ & $\begin{array}{l}\text { - To which component do students refer most? } \\
\text { - Which component triggers student review of other components? }\end{array}$ \\
\hline \multirow{5}{*}{$\begin{array}{l}\text { Task Level } \\
\text { (Taking } \\
\text { "Students } \\
\text { observe the } \\
\text { scenarios in } \\
\text { the presented } \\
\text { stimulus" as } \\
\text { an example) }\end{array}$} & $\begin{array}{l}\text { Satisfaction with resources } \\
\text { and perceived value }\end{array}$ & $\begin{array}{l}\text { - Are students satisfied with the resources? Do they consider them } \\
\text { useful? }\end{array}$ \\
\hline & Engagement in tasks & $\begin{array}{l}\text { - How many times do students access a specific learning activity or } \\
\text { resource? }\end{array}$ \\
\hline & $\begin{array}{l}\text { Achievement of assessment } \\
\text { tasks (assessment required) }\end{array}$ & - Do students master the knowledge about specific nutrients? \\
\hline & $\begin{array}{l}\text { Dynamics of epistemic } \\
\text { change }\end{array}$ & - How do student concepts about a specific nutrient change over time? \\
\hline & $\begin{array}{l}\text { Dynamics of group } \\
\text { interaction }\end{array}$ & $\begin{array}{l}\text { - How do students interact in their group to formulate good inquiry } \\
\text { questions? }\end{array}$ \\
\hline
\end{tabular}

\subsection{Step 5: Deciding On the Key LA Question(s)}

The purpose of connecting LA in LD is to answer questions regarding learning and learning design. Law et al. (2017) thus argue that LA questions formulated from the learning designer's perspective are a necessary bridge in connecting LD to LA. The LA taxonomy in our proposed framework provides a reference system for teachers to formulate LA questions that they consider important. Teachers begin by considering at which level the LA questions are located. Table 3 provides a list of possible LA questions relevant to different levels of granularity. At the curriculum unit level, teachers may be interested in 
students' overall performance as well as their perceived value of this unit. At the curriculum component level, teachers may be interested not only in student achievement of the component level learning outcomes but may also have LA questions regarding connections across different components. At the task level, teachers may have questions about student behaviour and performance in a specific task. For instance, how far are students engaged in the discussion forum? Does the discussion forum help students formulate their inquiry questions successfully? What concepts or theories do students use in their discussion?

It is important to note that some LA questions cannot be answered unless teachers have included the necessary assessment tasks in the LD. For instance, teachers need to implement a final assessment or specify how to compute the overall assessment score of a student's performance in a course if students' overall course performance is a required measure in the LA plan. At the task level, student achievement of a specific learning outcome can be evaluated through a multiple-choice quiz or an openended writing task (e.g., posting the inquiry question[s] formulated).

\subsection{Step 6: Selecting LA solutions}

Once the LA questions are defined in Step 5, teachers must select the relevant LA measures needed to answer the questions. For example, the teacher may be interested in which curriculum component has the strongest influence on students' overall course performance. Table 4 summarizes the LA data and techniques that can be used to provide LA measures at different levels of LD granularity. It is evident that the same set of data (e.g., student survey) may be used to generate LA measures at different levels. Similarly, the same techniques can be used to generate different measures. For example, social network analysis can be used to analyze students' social interactions within a group at the task level as well as to explore student resource access behaviour within and across different curriculum components.

Table 4. LA Data and Techniques for Different Levels of LD Granularity in “The Science of Cooking” Unit

\begin{tabular}{|c|c|c|c|}
\hline Levels of Granularity & LA Measures & Data To Be Collected & Example LA Techniques \\
\hline \multirow{3}{*}{ Course Level } & $\begin{array}{l}\text { Course performance } \\
\text { (assessment required) }\end{array}$ & $\begin{array}{l}\text { - Student's final } \\
\text { assessment/project }\end{array}$ & $\begin{array}{l}\text { - Descriptive analysis } \\
\text { - Inferential analysis }\end{array}$ \\
\hline & Aggregated course participation & - Student access to the LMS & $\begin{array}{l}\text { - Descriptive analysis } \\
\text { - Inferential analysis } \\
\text { - Temporal analysis }\end{array}$ \\
\hline & $\begin{array}{l}\text { Course satisfaction and } \\
\text { perceived value }\end{array}$ & - Student survey & $\begin{array}{l}\text { - Descriptive analysis } \\
\text { - Inferential analysis }\end{array}$ \\
\hline \multirow{3}{*}{$\begin{array}{l}\text { Curriculum } \\
\text { Component Level } \\
\text { (Taking "Formulate } \\
\text { inquiry questions by } \\
\text { goal setting" as an } \\
\text { example) }\end{array}$} & $\begin{array}{l}\text { Achievement of component } \\
\text { level LOs (assessment required) }\end{array}$ & $\begin{array}{l}\text { - Student assignment at the } \\
\text { end of the session }\end{array}$ & $\begin{array}{l}\text { - Descriptive analysis } \\
\text { - Inferential analysis }\end{array}$ \\
\hline & $\begin{array}{l}\text { Student engagement measures } \\
\text { across components }\end{array}$ & $\begin{array}{ll}\text { - } & \text { Student transition across } \\
\text { sessions }\end{array}$ & $\begin{array}{l}\text { - } \text { Temporal analysis } \\
\text { - Social network analysis }\end{array}$ \\
\hline & $\begin{array}{l}\text { Stop-review-resume trajectory } \\
\text { across components }\end{array}$ & $\begin{array}{l}\text { - Student transition across } \\
\text { sessions }\end{array}$ & $\begin{array}{ll}\text { - } & \text { Temporal analysis } \\
\text { - } & \text { Social network analysis } \\
\end{array}$ \\
\hline \multirow{5}{*}{$\begin{array}{l}\text { Task Level } \\
\text { (Taking "Students } \\
\text { observe the scenarios } \\
\text { in the presented } \\
\text { stimulus" as an } \\
\text { example) }\end{array}$} & $\begin{array}{l}\text { Satisfaction with resources and } \\
\text { perceived value }\end{array}$ & $\begin{array}{ll}\text { - } & \text { Student survey } \\
\text { - } & \text { Student access to the } \\
\text { resources }\end{array}$ & - Descriptive analysis \\
\hline & Engagement in tasks & $\begin{array}{l}\text { - Student access to } \\
\text { resources/learning activities }\end{array}$ & $\begin{array}{l}\text { - Descriptive analysis } \\
\text { - Temporal analysis }\end{array}$ \\
\hline & $\begin{array}{l}\text { Achievement of assessment } \\
\text { tasks (assessment required) }\end{array}$ & $\begin{array}{l}\text { - Student performance } \\
\text { - Student artifacts }\end{array}$ & $\begin{array}{l}\text { - Descriptive analysis } \\
\text { - Content analysis } \\
\text { - Thematic analysis }\end{array}$ \\
\hline & Dynamics of epistemic change & $\begin{array}{l}\text { - Student artifacts } \\
\text { - Student posts in the forum }\end{array}$ & $\begin{array}{l}\text { - } \text { Content analysis } \\
\text { - Thematic analysis } \\
\text { - Social network analysis }\end{array}$ \\
\hline & Dynamics of group interaction & - Student posts in the forum & $\begin{array}{l}\text { - Social network analysis } \\
\text { - Discourse analysis } \\
\end{array}$ \\
\hline
\end{tabular}

\subsection{Step 7: Alignment Check}

LA questions can only be answered if the necessary measures and data required are available, which depends on the design decisions. To provide guidance to teachers in their selection and adoption of LA to enhance learning and LD, the LA-CCDP patterns provide recommendations and guidance to teachers about LA measures and techniques relevant to the approaches and 
strategies included in the pattern. The patterns also flag issues if the design decisions made do not include the necessary data for computing the required measures.

\subsection{LA-CC and LA-CCDP}

We have now described the process of developing the five components of the curriculum unit for "The Science of Cooking." Section 4.2 describes the process of constructing five LA-CCs as the main sequence of curriculum components (CCs). Section 4.3 then describes the determination of the sequence of four tasks in the first $\mathrm{CC}$ on formulating inquiry questions by goal setting. While the specifics of some task settings in step 4 (described in section 4.4) are closely related to the disciplinary knowledge content for "The Science of Cooking," the task sequence, the elements of the task setting, LA questions, and LA solutions unrelated to the subject matter content would be reusable in other learning contexts where students formulate inquiry questions by goal setting. For LA questions related to the subject matter, both the questions and the same LA tools would likely still be relevant. Only the specific subject matter terms and resources need to be replaced in the task and tool settings. Thus, by removing the specific subject matter content reference, we can construct an LA-CCDP for "formulate inquiry questions by goal setting" that would apply to learning designs in STEM subjects.

\section{Discussion and Conclusion}

In this paper, we have reviewed the rich literature on learning analytics that focuses on learning design and its conceptual frameworks. Based on these findings, as well as our own design-based implementation research with STEM teachers on learning design, we have put forward an LA-integrated LD framework to "connect learning design and learning analytics, bridge the gap between theory and practice, and/or offer guidance in use, interpretation of and reflection on learning analytics for refinement and redesign of learning activities," as requested in the call for papers for this issue. While the proposed framework is yet to be empirically tested in its entirety, our proposal possesses important features that can be included in any framework that meets the challenge. The critical characteristics of such frameworks include the following: 1) a multilevel structure that matches the complex, multilevel nature of learning design; 2) explicit connections and guidance for LD decisions at the different LD levels; 3) integration of the LA taxonomy and LA design decisions into the LD framework and process; 4) mechanisms to create/document LD patterns that encompass a coherent set of technological-pedagogical content decisions embedded into the design elements for easy adoption and customization; and 5) a procedural guide for operationalizing the LD process that can help teachers focus on the core pedagogical decisions.

LA-integrated LD frameworks can be adopted by teachers, learning designers, and teacher educators to scaffold LD practice as well as for pre- and in-service teacher education. It can also be used to design repositories of LDs for easy review, sharing, and adoption. Such repositories can serve as a knowledge management space for communities of practice. Given the LA-integration element in the framework, both the framework and representations of examples of "closing the loop" would help teachers to understand and adopt LA in their own professional practice. In addition to providing just-in-time feedback to students to provide more appropriate, personalized, and LD-relevant feedback (e.g., Liu \& Koedinger, 2017; Shibani, Knight, \& Buckingham Shum, 2019), LA integrated learning systems can also provide students with the freedom to choose or configure LD-relevant LAs and associated visualizations for their own learning. Just-in-time feedback can also support teachers in their real-time classroom orchestration if used appropriately during the LD stage (Prieto, Rodríguez-Triana, Martínez-Maldonado, Dimitriadis, \& Gašević, 2019; Mavrikis, Geraniou, Gutierrez Santos, \& Poulovassilis, 2019).

The framework can also be adopted by researchers in their analysis of LDs, including those with LA elements, such as in research on teacher growth and development in their design understanding and practice. It can also be used to guide learning technology developers in designing learning management systems and LA and associated visualization tools. Such a framework is particularly useful in supporting interoperability of different technology tools to form an integrated system to deliver LA-based and pedagogically relevant feedback to teachers and learners.

An important limitation of such frameworks is that they are relatively complex, and would not be readily adopted by practitioners unless realized on a platform that can actively connect teachers to relevant curriculum component patterns, guiding them by highlighting the most important design decisions while minimizing the cognitive demand of less important details. As teachers become more proficient, they can examine and modify the designs at any level of granularity and contribute new or modified LDs and patterns. Another challenge to the adoption of such frameworks is the relative isolation of the LD and LA practitioner communities.

The LA-integrated LD framework is still at a preliminary stage of development, particularly the LA components in the LDT. Further piloting of the framework with different stakeholder groups would be necessary to gauge its utility as well as to refine it. Further directions for research and development include the curation of successful "completing the loop" practice examples to provide design representations, and possibly to extract design patterns for more general dissemination. Another very important direction for future work is the development of technology systems that integrate an LD authoring tool, a 
learning management system, and LA-cum-visualization components into one system to support different stakeholders to work productively together.

\section{Declaration of Conflicting Interest}

The author(s) declared no potential conflicts of interest with respect to the research, authorship, and/or publication of this article.

\section{Funding}

The publication of this article received financial support from the Innovation and Technology Commission of the Hong Kong SAR Government, under the Innovative Technology Fund, grant number ITS/388/17FP.

\section{Acknowledgments}

The authors would like to acknowledge the support provided by colleagues at the Centre for Information Technology in Education, University of Hong Kong, and in particular Mr. Andy Chan, for the support they have rendered to us in this work.

\section{References}

Ahn, J., Campos, F., Hays, M., \& DiGiacomo, D. (2019). Designing in context: Reaching beyond usability in learning analytics dashboard design. Journal of Learning Analytics, 6(2), 70-85. https://dx.doi.org/10.18608/jla.2019.62.5

Alexander, C. (1977). A pattern language: Towns, buildings, construction. Oxford, UK: Oxford University Press.

Barrows, H. S. (1986). A taxonomy of problem-based learning methods. Medical Education, 20(6), 481-486. https://dx.doi.org/10.1111/j.1365-2923.1986.tb01386.x

Bower, M., Craft, B., Laurillard, D., \& Masterman, L. (2011). Using the learning designer to develop a conceptual framework for linking learning design tools and system. In L. Cameron \& J. Dalziel (Eds.), Proceedings of the 6th International LAMS \& Learning Design Conference: Learning Design for a Changing World, 8-9 December 2011, Sydney, Australia (pp. 61-71). Sydney, Australia: LAMS Foundation. Retrieved from https://researchers.mq.edu.au/en/publications/using-the-learning-designer-to-develop-a-conceptual-framework-for

Boyle, T. (2010). Layered learning design: Towards an integration of learning design and learning object perspectives. Computers \& Education, 54(3), 661-668. https://dx.doi.org/10.1016/j.compedu.2009.09.026

Buckingham Shum, S., Ferguson, R., \& Martinez-Maldonado, R. (2019). Human-centred learning analytics. Journal of Learning Analytics, 6(2), 1-9. https://dx.doi.org/10.18608/jla.2019.62.1

Charlton, P., Magoulas, G., \& Laurillard, D. (2012). Enabling creative learning design through semantic technologies. Technology, Pedagogy and Education, 21(2), 231-253. https://dx.doi.org/10.1080/1475939x.2012.698165

Corrin, L., Kennedy, G., de Barba, P. G., Lockyer, L., Gašević, D., Williams, D., \& Bakharia, A. (2016). Completing the loop: Returning meaningful learning analytic data to teachers. Sydney: Office for Learning and Teaching. Retrieved from http://melbourne-cshe.unimelb.edu.au/ data/assets/pdf file/0006/2083938/Loop Handbook.pdf

Cross, S., Galley, R., Brasher, A., \& Weller, M. (2012). The final report of the OULDI-JISC project: Challenge and change in curriculum design process. Bristol, UK: JISC.

Dalziel, J. (2013). Implementing learning design: A decade of lessons learned. Proceedings of the $30^{\text {th }}$ Annual Conference of the Australasian Society for Computers in Learning in Tertiary Education (ASCILITE 2013) 1-4 December 2013, Sydney, Australia (pp. 210-220). Australasian Society for Computers in Learning in Tertiary Education. Retrieved from https://www.ascilite.org/conferences/sydney13/program/papers/Dalziel,\%20James.pdf

Earl, L. M. (2012). Assessment as learning: Using classroom assessment to maximize student learning. Thousand Oaks, CA: Corwin Press.

Gibson, A., Kitto, K., \& Willis, J. (2014). A cognitive processing framework for learning analytics. Proceedings of the $4^{\text {th }}$ International Conference on Learning Analytics and Knowledge (LAK '14), 24-28 March 2014, Indianapolis, IN, USA (pp. 212-216). New York, NY: ACM. https://dx.doi.org/10.1145/2567574.2567610

Goodyear, P. (2005). Educational design and networked learning: Patterns, pattern languages and design practice. Australasian Journal of Educational Technology, 21(1), 82-101. https://dx.doi.org/10.14742/ajet.1344

Goodyear, P., \& Retalis, S. (2010). Technology-enhanced learning: Design patterns and pattern languages. Rotterdam, Netherlands: Sense Publishers.

Gruber, T. R. (1995). Toward principles for the design of ontologies used for knowledge sharing? International Journal of Human-Computer Studies, 43(5-6), 907-928. https://dx.doi.org/10.1006/ijhc.1995.1081 
Haya, P. A., Daems, O., Malzahn, N., Castellanos, J., \& Hoppe, H. U. (2015). Analysing content and patterns of interaction for improving the learning design of networked learning environments. British Journal of Educational Technology, 46(2), 300-316.

Hernández-Leo, D., Harrer, A., Dodero, J. M., Asensio-Pérez, J. I., \& Burgos, D. (2007). A framework for the conceptualization of approaches to "Create-by-Reuse" of learning design solutions. Journal of Universal Computer Science, 13(7), 991-1001. Retrieved from https://citeseerx.ist.psu.edu/viewdoc/download?doi=10.1.1.114.1937\&rep=rep1\&type=pdf

Hew, K. F., Law, N., Wan, J., Lee, Y., \& Kwok, A. (2016). Self-directed learning in science education: Explicating the enabling factors. Singapore: International Society of the Learning Sciences.

Hmelo-Silver, C. E. (2004). Problem-based learning: What and how do students learn? Educational Psychology Review, 16(3), 235-266. https://dx.doi.org/10.1023/b:edpr.0000034022.16470.f3

Inventado, P. S., \& Scupelli, P. (2015). Data-driven design pattern production: A case study on the ASSISTments online learning system. Proceedings of the 20th European Conference on Pattern Languages of Programs (EuroPLoP '15), 8-12 July 2015, Kaufbeuren, Germany (Article No. 14). New York, NY: ACM. https://dx.doi.org/10.1145/2855321.2855336

Koedinger, K. R., Stamper, J. C., McLaughlin, E. A., \& Nixon, T. (2013). Using data-driven discovery of better student models to improve student learning. In H. C. Lane, K. Yacef, J. Mostow, \& P. Pavlik (Eds.), Proceedings of the $16^{\text {th }}$ International Conference on Artificial Intelligence in Education (AIED '13), 9-13 July 2013, Memphis, TN, USA (pp. 421-430). Berlin, Germany: Springer.

Koehler, M., \& Mishra, P. (2009). What is technological pedagogical content knowledge (TPACK)? Contemporary Issues in Technology and Teacher Education, 9(1), 60-70.

Krathwohl, D. R. (2002). A revision of Bloom's taxonomy: An overview. Theory into Practice, 41(4), 212-218. https://dx.doi.org/10.1207/s15430421tip4104_2

Laurillard, D. (2013). Teaching as a design science: Building pedagogical patterns for learning and technology. New York, NY: Routledge.

Law, N., Li, L., Farias Herrera, L., Chan, A., \& Pong, T. C. (2017). A pattern language based learning design studio for an analytics informed inter-professional design community. Interaction Design and Architecture(s), 33, 92-112.

Liu, R., \& Koedinger, K. R. (2017). Closing the loop: Automated data-driven cognitive model discoveries lead to improved instruction and learning gains. Journal of Educational Data Mining, 9(1), 25-41. https://dx.doi.org/10.5281/zenodo.3554625

Lockyer, L., \& Dawson, S. (2012). Where learning analytics meets learning design. In S. Buckingham Shum, D. Gašević, \& R. Ferguson (Eds.), Proceedings of the $2^{\text {nd }}$ International Conference on Learning Analytics and Knowledge (LAK '12), 29 April-2 May 2012, Vancouver, BC, Canada (pp. 14-15). New York, NY: ACM. https://dx.doi.org/10.1145/2330601.2330609

Lockyer, L., Heathcote, E., \& Dawson, S. (2013). Informing pedagogical action: Aligning learning analytics with learning design. American Behavioral Scientist, 57(10), 1439-1459. https://dx.doi.org/10.1177/0002764213479367.

Mangaroska, K., \& Giannakos, M. N. (2019). Learning analytics for learning design: A systematic literature review of analytics-driven design to enhance learning. IEEE Transactions on Learning Technologies, 12(4), 516-534. https://dx.doi.org/10.1109/TLT.2018.2868673

Mavrikis, M., Geraniou, E., Gutierrez Santos, S., \& Poulovassilis, A. (2019). Intelligent analysis and data visualization for teacher assistance tools: The case of exploratory learning. British Journal of Educational Technology, 50(6), 29202942. https://dx.doi.org/10.1111/bjet.12876

Mor, Y., Mellar, H., Warburton, S., \& Winters, N. (2014). Practical design patterns for teaching and learning with technology. Rotterdam, The Netherlands: Sense Publishers. https://dx.doi.org/10.1007/978-94-6209-530-4

Nguyen, A., Gardner, L. A., \& Sheridan, D. (2017). A multilayered taxonomy of learning analytics applications. Proceedings of the 21st Pacific-Asia Conference on Information Systems (PACIS 2017), 16-20 July 2017, Langkawi Island, Malaysia (Article No. 54). Atlanta, Georgia: Association for Information Systems (AIS). Retrieved from https://aisel.aisnet.org/pacis2017/54

Pilling-Cormick, J., \& Garrison, D. R. (2007). Self-directed and self-regulated learning: Conceptual links. Canadian Journal of University Continuing Education, 33(2), 13-33. https://dx.doi.org/10.21225/D5S01M

Peña-Ayala, A. (2018). Learning analytics: A glance of evolution, status, and trends according to a proposed taxonomy. Data Mining and Knowledge Discovery, 8(3), e1243. https://dx.doi.org/10.1002/widm.1243 
Prieto, L. P., Rodríguez-Triana, M. J., Martínez-Maldonado, R., Dimitriadis, Y., \& Gašević, D. (2019). Orchestrating learning analytics (OrLA): Supporting inter-stakeholder communication about adoption of learning analytics at the classroom level. Australasian Journal of Educational Technology, 35(4), 14-33.

https://dx.doi.org/https://doi.org/10.14742/ajet.4314

Rehrey, G., Shepard, L., Hostetter, C., Reynolds, A., \& Groth, D. (2019). Engaging faculty in learning analytics: Agents of institutional culture change. Journal of Learning Analytics, 6(2), 86-94. http://dx.doi.org/10.18608/jla.2019.62.6

Rienties, B., Nguyen, Q., Holmes, W., \& Reedy, K. (2017). A review of ten years of implementation and research in aligning learning design with learning analytics at the Open University UK. Interaction Design and Architecture(s), 33, 134154.

Rienties, B., \& Toetenel, L. (2016). The impact of learning design on student behaviour, satisfaction and performance: A cross-institutional comparison across 151 modules. Computers in Human Behavior, 60, 333-341. https://dx.doi.org/10.1016/j.chb.2016.02.074

Rienties, B., Toetenel, L., \& Bryan, A. (2015). Scaling up learning design: Impact of learning design activities on LMS behavior and performance. Proceedings of the $5^{\text {th }}$ International Conference on Learning Analytics and Knowledge (LAK ’15), 16-20 March 2015, Poughkeepsie, NY, USA (pp. 315-319). New York, NY: ACM. http://dx.doi.org/doi:10.1145/2723576.2723600

Rosé, C. P., McLaughlin, E. A., Liu, R., \& Koedinger, K. R. (2019). Explanatory learner models: Why machine learning (alone) is not the answer. British Journal of Educational Technology, 50(6), 2943-2958. http://dx.doi.org/10.1111/bjet.12858

Seufert, S., Meier, C., Soellner, M., \& Rietsche, R. (2019). A pedagogical perspective on big data and learning analytics: A conceptual model for digital learning support. Technology, Knowledge and Learning, 24(4), 599-619. https://dx.doi.org/10.1007/s10758-019-09399-5

Shibani, A., Knight, S., Buckingham Shum, S., \& Ryan, P. (2017). Design and implementation of a pedagogic intervention using writing analytics. In W. Chen et al. (Eds.), Proceedings of the $25^{\text {th }}$ International Conference on Computers in Education (ICCE 2017), 4-8 December 2017, Christchurch, New Zealand (pp. 306-315). Jhongli City, Taiwan: AsiaPacific Society for Computers in Education.

Shibani, A., Knight, S., \& Shum, S. B. (2019). Contextualizable learning analytics design: A generic model and writing analytics evaluations. Proceedings of the $9^{\text {th }}$ International Conference on Learning Analytics and Knowledge (LAK '19), 4-8 March 2019, Tempe, Arizona, USA (pp. 210-219). New York, NY: ACM. https://dx.doi.org/10.1145/3303772.3303785

Shuler, C. F. (2012). Comparisons in basic science learning outcomes between students in PBL and traditional dental curricula at the same dental school. In S. Bridges, C. McGrath \& T. Whitehill (Eds.), Problem-Based Learning in Clinical Education (pp. 35-46). Dordrecht, The Netherlands: Springer. http://dx.doi.org/10.1007/978-94-007-2515$\underline{7} 3$

Spady, W. (1993). Outcome-based education. Belconnen, ACT: Australian Curriculum Studies Association.

Toetenel, L., \& Rienties, B. (2016). Learning design: Creative design to visualise learning activities. Open Learning: The Journal of Open, Distance and e-learning, 31(3), 233-244. http://dx.doi.org/10.1080/02680513.2016.1213626 